\title{
心拍変動の不等間隔周波数解析法の提案と 副交感神経遮断によるスペクトル変化
}

\author{
○今 重之, 富田 豊, 本多 敏, 岡島 康友 (慶応大学) \\ A new spectrum analysis method for heart rate variability \\ and its change with parasympatholytic agents \\ Shigeyuki Kon, Yutaka Tomita, Satoshi Honda, Yasutomo Okajima(Keio Univ.)
}

\section{1.はじめに}

様々な作業において, 作業の精神的負担を定 量的に評価するために，心拍の変動 (Heart Rate Variability: HRV)をスペクトル解析する 方法がある。

心拍は時間とともに変動するので, サンプリ ングが不等時間間隔である.不等時間間隔でサ ンプリングされた時系列データは一般にはフ ーリエ変換できない. そこで, 心拍変動をスペ クトル解析するために, いくつかの方法が提案 されている.すでに報告された方法のうち,お おくのものは, 不等時間間隔の時系列をスプラ イン補間法などを用いて等時間間隔の時系列 にサンプリングし直して FFT を行なう方法が ある. しかし，この場合に推定スペクトルが変 化しない保証はない。

そこで,われわれは不等時間間隔の時系列の まま,離散フーリエ変換を行なう方法を提案し $た^{1)}$.

今回，提案した方法を用いて，健常人と副交 感神経遮断剂服用者の HRV について周波数解 析を行った.

\section{2. 不等時間間隔信号の周波数解析につ} いて

われわれが提案した方法を概述する.詳細は 文献 1 )に述べた。

不等時間間隔の時系列 $\left\{x\left(t_{n}\right)\right\}$ の周波数軸
への変換は, 周波数 $k / P$ におけるスペクトルを $C_{k}$ とすると, フーリエ積分を近似して

$$
C_{k}=(1 / P) \sum_{n=0}^{N-1} x\left(t_{n}\right) \exp (-i k 2 \pi / P)\left(t_{n+1}-t_{n}\right)
$$

と表す.ただし， $t_{n}$ は $n$ 番目の事象が発生し た時刻， $P$ は全観測時間, すなわち $P=T_{N-1}$ で ある。

3. 心拍の取得および心拍変動スペクト ラム

健常男子 (48 歳) および心房細動治療のた め副交感神経遮断剂を服用している患者 (43 歳)より，安静座位の状態で 1 時間にわたって 心電図を記録し，R-R 間隔を取得した。健常者 の結果を図 $1 \mathrm{a}$ に, 患者の副交感神経遮断剂服 用中の結果を同 $\mathrm{b} に$, 同剤の服用を中断し wash out した状態での結果を同 $\mathrm{c}$ に示す.

さらに,それぞれの心拍変動スペクトラムを 図 $1 \mathrm{~d}, e, f$ に示す.

a， d から，健常人では $0.3 \mathrm{~Hz}$ 近傍に呼吸性 の変動が, $0.1 \mathrm{~Hz}$ 近傍に自律神経系の応答が 現れていることがわかる.副交感神経遮断剤服 用者では，変動が減少し（図 b,e），同剤の 服用を中断したとき(図 $\mathrm{c}, \mathrm{f}$ ) の半分程度にな っている. 
参考文献

1）今 他: 不等時間間隔のフーリエ変換, 日
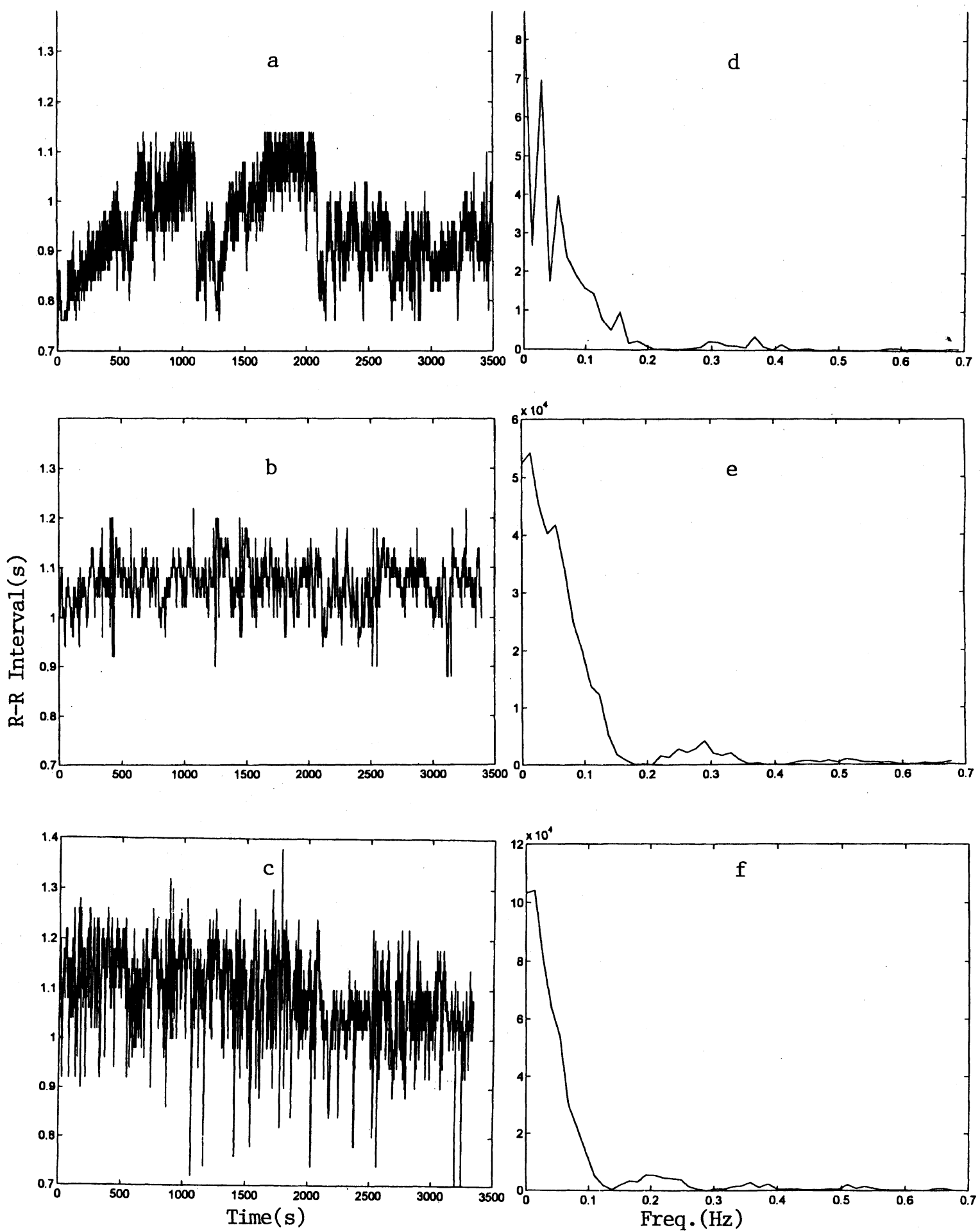

Fig.1 R-R Interval and Its Spectrum 